\title{
Synthesis of Polyesters by E mulsion Polycondensation Reaction in Water
}

\author{
Hozumi TANAKA ${ }^{\dagger, \dagger \dagger}$ and Toru KURIHASHI \\ Tsukuba Research Laboratories, TOYO INK MFG., CO. LTD., 27 Wadai, Tsukuba, Ibaraki 300-4247, Japan
}

(Received August 8, 2002; Accepted February 17, 2003)

\begin{abstract}
Polyesters were prepared from dicarboxylic acids and diols in the presence of a surfactant under mild conditions below $100^{\circ} \mathrm{C}$ in water. The results of polycondensation on various conditions in the presence of $p$ dodecylbenzenesulfonic acid(DBSA) show that polyesters were obtained in a good yield from sebacic acid and decanediol in water at $70^{\circ} \mathrm{C}$. The molecular weight of the resulting polyesters were approximately $2000-5000$ by gel permeation chromatography (GPC) in a chloroform eluent. The molecular weight distribution from this emulsion polycondensation was below $M_{\mathrm{w}} / M_{\mathrm{n}}=2.0$. The particle size of these misells from this emulsion polycondensation were $c a$. $4-6 \mu \mathrm{m}$. Esterfication in water might occur in misells having hydrophobic media from DBSA, which may play a role as the catalyst of esterification and also misell formation for this emulsion polycondensation in a water medium.
\end{abstract}

KEY WORDS Direct Polycondensation / Polyester / Misell / Surfactant / Emulsion /

p-Dodecylbenznesulfonic Acid /

Polycondensation reactions are generally carried out in a molten state of elevated temperature above $200^{\circ} \mathrm{C}$ since the reaction are usually accompanied by an equilibrium between esterification and hydrolysis reactions. The enhancement of monomer reactivity can be achieved by using active reagents such as the combination of hexachloroethane and triphenylphosphine or picryl chloride in pyridine so that a polycondensation reaction takes place under mild conditions by direct polycondensation. ${ }^{1-10}$ The synthesis of aliphatic polyesters was performed by a dehydrogenation polycondensation in water using lipase as a catalyst. ${ }^{11,12}$ Recently, it was found that a condensation reaction takes place in water directly between acid and alcohol to form an ester compound in the presence of a surfactant such as $p$-dodecylbenzenesulfonic acid(DBSA) under mild conditions. ${ }^{13-15}$ In this paper, we employ direct polycondensation to prepare polyesters with out the use of reagents for dehydration in organic solvents. This reaction using the surfactant(DBSA) was applied to the polycondensation of dicarboxylic acids and diols and it was found that polyesters could be obtained under mild conditions below $100^{\circ} \mathrm{C}$ in water as follows:

Surfactant

$$
\begin{gathered}
\mathrm{HO}-\mathrm{R}-\mathrm{OH}+\mathrm{HOOC}-\mathrm{R}^{\prime}-\mathrm{COOH} \rightarrow \\
{\left[-\mathrm{O}-\mathrm{R}-\mathrm{OCO}-\mathrm{R}^{\prime}-\mathrm{CO}-\right]+2 \mathrm{H}_{2} \mathrm{O}} \\
\text { in Water. }
\end{gathered}
$$

\section{EXPERIMENTAL}

\section{Materials}

Succinic acid, sebacic acid, adipic acid, isophthalic

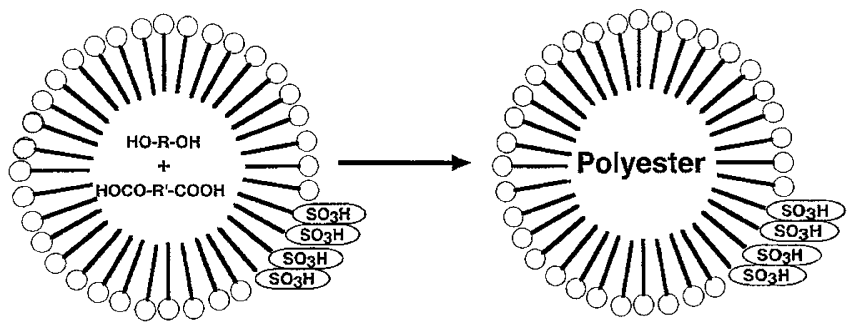

Figure 1. Illustration of emulsion polycondensation by dehydration in the presence of a surfactant in water.

acid, terephthalic acid, hexanediol, decanediol, and bisphenol-A were used without further purification and deionized water was used.

\section{Polymerization Procedure}

A $0.01 \mathrm{~mol}$ of sebacic acid, $0.01 \mathrm{~mol}$ decanediol, and $0.60 \mathrm{~g}$ of $p$-dodecylbenzenesulfonic acid(DBSA) were added to $50 \mathrm{~g}$ of deionized water in a $200 \mathrm{~mL}$ of Erlenmeyer flask with stirring at $70^{\circ} \mathrm{C}$. After a given period of time, the excess methanol in the reaction mixture was added to remove the unreacted monomers and byproducts from the polymer which was then isolated by filtration. The polymers were washed repeatedly with methanol and then dried at $50^{\circ} \mathrm{C}$ for $6 \mathrm{~h}$.

\section{Characterization}

The number-average $\left(M_{\mathrm{n}}\right)$ and weight-average $\left(M_{\mathrm{w}}\right)$ molecular weight were determined by GPC using a TOSOH SC- 8020 at $40^{\circ} \mathrm{C}$ in chloroform as calibrated with polystyrene standards. FT-IR spectra were recorded for film samples cast on an $\mathrm{NaCl}$ disk from a chloroform solution, using JASCO FT/IR-300E spec-

\footnotetext{
${ }_{\dagger}^{\dagger}$ To whom correspondence should be addressed (Fax: +81-847-45-5211, E-mail: h-tanaka@yschem.co.jp).

${ }^{\dagger}$ Present Address: Department of Research \& Development YASUHARA CHEMICAL CO., LTD., 1080 Takagi-cho, Fuchu, Hiroshima 726-8632, Japan.
} 
Table I. Polycondensation of sebacic acid and decanediol with DBSA or DBSANa in water

\begin{tabular}{|c|c|c|c|c|c|c|c|}
\hline \multirow{2}{*}{$\begin{array}{c}\text { Decanediol } \\
\text { Mol }\end{array}$} & \multirow{2}{*}{$\begin{array}{c}\text { DBSA } \\
\mathrm{g}\end{array}$} & \multirow{2}{*}{$\begin{array}{c}\text { DBSANa } \\
\mathrm{g}\end{array}$} & \multicolumn{2}{|c|}{ Condition } & \multirow{2}{*}{$\frac{\text { Yield }}{\%}$} & \multicolumn{2}{|c|}{ Molecular weight } \\
\hline & & & $\operatorname{Temp}\left({ }^{\circ} \mathrm{C}\right)$ & Time(h) & & $\overline{M_{\mathrm{w}}}$ & $\overline{M_{\mathrm{w}} / M_{\mathrm{n}}}$ \\
\hline 0.01 & 0.60 & - & 70 & 70 & 81 & 2400 & 1.88 \\
\hline 0.01 & 0.33 & - & 70 & 70 & 85 & 3000 & 1.73 \\
\hline 0.01 & 0.66 & - & 15 & 70 & 0 & - & - \\
\hline 0.02 & 0.63 & - & 70 & 20 & 83 & 2800 & 1.67 \\
\hline 0.02 & - & 0.60 & 70 & 20 & 0 & - & - \\
\hline 0.02 & - & - & 70 & 70 & 0 & - & - \\
\hline
\end{tabular}

DBSA; $p$-Dodecylbenezenesulfonic acid. DBSANa; $p$-Dodecylbenezenesulfonic acid sodium salt.

Table II. Polycondensation of various dicarboxylic acid derivatives with DBSA in water

\begin{tabular}{lccccccc}
\hline Dicarboxylic acid & $\begin{array}{c}\text { Solubility } \\
\text { in Water }\end{array}$ & \multicolumn{2}{c}{ Acidity } & \multicolumn{2}{c}{ Condition Yield } & \multicolumn{2}{c}{ Molecular weight } \\
\hline & $\mathrm{g} /{ }^{\circ} \mathrm{C}$ & $\mathrm{p} K 1$ & $\mathrm{p} K 2$ & Time $(\mathrm{h})$ & $\%$ & $M_{\mathrm{w}}$ & $M_{\mathrm{w}} / M_{\mathrm{n}}$ \\
Succinic acid & $6.8 / 20$ & 4.21 & 5.64 & 20 & 17 & 1300 & 1.62 \\
Adipic acid & $1.4 / 15$ & 4.43 & 5.41 & 19 & 24 & 1850 & 1.36 \\
Sebacic acid & $0.1 / 20$ & 4.60 & 5.59 & 20 & 83 & 2800 & 1.67 \\
Isophthalic acid & $0.01 / 25$ & 3.62 & 4.60 & 20 & 0 & - & - \\
Terephthalic acid & $0 / 20$ & 3.54 & 4.46 & 19 & 0 & - & - \\
\hline
\end{tabular}

Polycondensation; monomer concentration : $0.01 \mathrm{~mol}$ in $50 \mathrm{~g}$ of water at $70^{\circ} \mathrm{C}$. Solubility; in $100 \mathrm{~g}$ of water.

trometer. The structure of polyesters was determined by NMR using JEOL Lambda $600 \mathrm{MHz}$. In $\mathrm{CDCl}_{3}$ as the standard of TMS. The particle sizes of misells from the emulsion polycondensation were determined by Laser particle analyzer LPA-3100 made by Otuka Electronics.

\section{RESULTS AND DISCUSSION}

Table I summarizes the results of polycondensation of sebacic acid and decanediol in the presence of DBSA or DBSANa, where it is seen that the resulting polyesters were obtained in a good yield at $70^{\circ} \mathrm{C}$ at room temperature $\left(15^{\circ} \mathrm{C}\right)$ and when of surfactants or DBSANa were used in place of DBSA, no satisfactory results in terms of polymer yield were obtained. Weight average $\left(M_{\mathrm{w}}\right)$ molecular weights were determined to be approximately 3000 by GPC analysis and the molecular weight distribution from this condition had a narrow distribution below $M_{\mathrm{w}} / M_{\mathrm{n}}=2.0$.

Table II shows the results of emulsion polycondensation of various dicarboxylic acids and decanediol in the presence of DBSA in water. Sebacic acid gave polyesters having a high yield and high molecular weight compaired with adipic acid or succinic acid in this polycondensation reaction. These results suggest that the solubility and hydrophobic property of acid derivatives in water may be related to this emulsion polycondensation reaction. Aromatic acids such as terephthalic acid or isophthalic acid did not yield polyesters because of poor solubility in water and in the

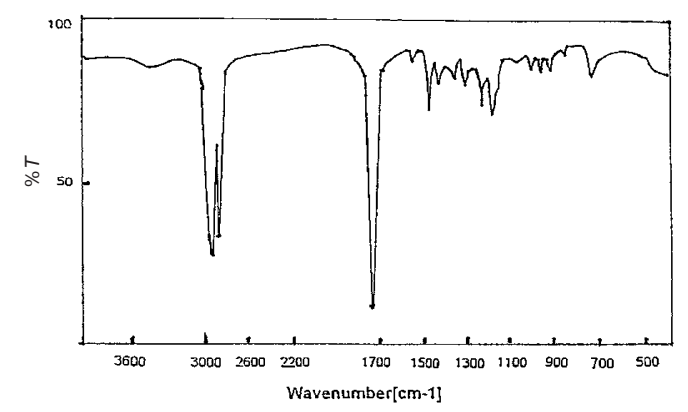

Figure 2. IR spectrum of polyesters with sebacic acid and decanediol.

misell in this condition. The acidity of acid derivatives were not important in this emulsion polycondensation, as shown in Table II.

The IR spectrum of polyesters with sebacic acid and decanediol is shown Figure 2. Which was identified by an adsorption at $1736 \mathrm{~cm}^{-1}$ due to the ester grouping the polymer chain. The structure of polyesters having straight chains was determined by NMR analysis as shown Figure 3. The spectrum of NMR had proton signals of $2.60 \mathrm{ppm}$ and $4.05 \mathrm{ppm}$ (from polyesters), $2.74 \mathrm{ppm}$ (from sebacic acid), and $3.65 \mathrm{ppm}$ (from decanediol) respectively.

The calculated molecular weight of polyester $\left(M_{\mathrm{w}}=\right.$ $c a$. 2400) by NMR value gave approximately the same molecular weight $\left(M_{\mathrm{w}}=c a .2600\right)$ by GPC analysis.

The results of polycondensation with various diopls and sebasic acid in the presence of DBSA in water are shown in Table III. Bis-phenol-A having a phenolic hydroxy group, did not yield polyesters under this condi- 
Synthesis of Polyesters

Table III. Polycondensation of various diols and sebacic acid in the presence of DBSA in water

\begin{tabular}{|c|c|c|c|c|c|c|}
\hline \multirow{2}{*}{ Diol } & \multirow{2}{*}{$\begin{array}{l}\text { Solubility } \\
\text { in Water }\end{array}$} & \multirow{2}{*}{$\begin{array}{l}\text { Melting point } \\
\text { of diols }\left({ }^{\circ} \mathrm{C}\right)\end{array}$} & \multirow{2}{*}{$\begin{array}{c}\text { Condition } \\
\text { Time(h) }\end{array}$} & \multirow{2}{*}{$\frac{\text { Yield }}{\%}$} & \multicolumn{2}{|c|}{ Molecular weight } \\
\hline & & & & & $M_{\mathrm{w}}$ & $\overline{M_{\mathrm{w}} / M_{\mathrm{n}}}$ \\
\hline Hexanediol & soluble & $42-43$ & 50 & 5 & - & - \\
\hline Decanediol & slight soluble & $72-73$ & 65 & 85 & 3000 & 1.36 \\
\hline Bis-Phenol-A & insoluble & 128 & 21 & 0 & - & - \\
\hline
\end{tabular}

Polycondensation; monomer concentration: $0.01 \mathrm{~mol}$ in $50 \mathrm{~g}$ of water at $70^{\circ} \mathrm{C}$.

Table IV. Results of homogeneous condition of sebacic acid, decanediol, and DBSA in polycondensation

\begin{tabular}{|c|c|c|c|c|}
\hline \multirow{2}{*}{$\begin{array}{l}\text { Monomer } \\
\text { Condition }\end{array}$} & \multirow{2}{*}{$\frac{\text { Time }}{\mathrm{h}}$} & \multirow{2}{*}{$\frac{\text { Yield }}{\%}$} & \multicolumn{2}{|c|}{ Molecular weight } \\
\hline & & & $M_{\mathrm{W}}$ & $M_{\mathrm{w}} / M_{\mathrm{n}}$ \\
\hline Equimolecular & 22 & 91 & 2400 & 1.45 \\
\hline $5 \mathrm{~mol} \%$ excess of sebacic acid & 19 & 92 & 3200 & 1.54 \\
\hline $10 \mathrm{~mol} \%$ excess of sebacic acid & 23 & 85 & 2600 & 1.52 \\
\hline $5 \mathrm{~mol} \%$ excess of decanediol & 23 & 91 & 3200 & 1.52 \\
\hline DBSA in water medium & 18 & 86 & 2800 & 1.47 \\
\hline
\end{tabular}

Polycondensation; monomer concentration : $0.04 \mathrm{~mol}$ in $50 \mathrm{~g}$ of water at $80^{\circ} \mathrm{C}$ in the presence of $0.60 \mathrm{~g}$ of DBSA. Homogeneous Condition; Sebacic acid, decanediol, and DBSA were melted for $5 \mathrm{~min}$ at $150^{\circ} \mathrm{C}$, and then poured into water at $70^{\circ} \mathrm{C}$.

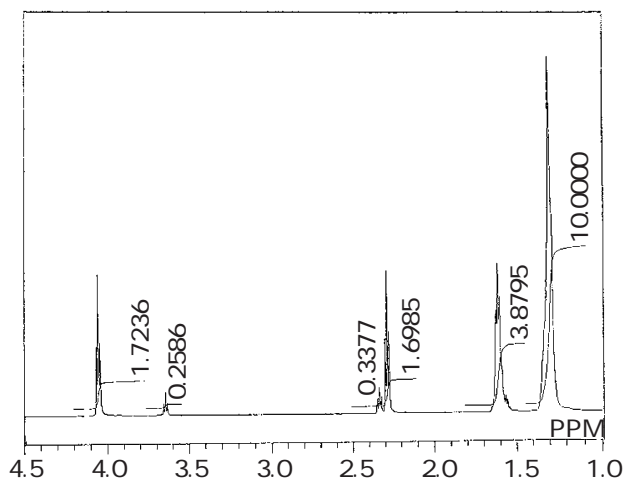

Figure 3. NMR spectrum of polyesters with sebacic acid and decanediol.

tion while hexanediol (dissolved in water) gave a small amount of polymers (5\% yield). Decanediol having a hydrophobic carbon chain, dissolves slightly in water. Therefore, decanediol dissolved in the misell of DBSA together with dicarboxylic acids in water. This emulsion polycondensation starts in heterogeneous media in water because of the poor solubility of monomers in water. Furthermore, the mole balance in this polycondensation reaction is very important for the preparation of high-molecular-weight polymer.

The results of mole balance of monomers was shown Table IV. Sebacic acid, decanediol, and DBSA were melted to be controlled the mole balance in the misell for $5 \mathrm{~min}$ at $150^{\circ} \mathrm{C}$ (homogeneous condition) and then the mixture was poured into water at $70^{\circ} \mathrm{C}$. The molecular weight of polymers from a $5 \mathrm{~mol} \%$ excess of sebacic acid or a $5 \mathrm{~mol} \%$ excess of decanediol were obtained as $M_{\mathrm{W}}=3200$ and $M_{\mathrm{w}} / M_{\mathrm{n}}=1.5$ respectively.

Table V shows the results of the polycondensation of sebacic acid and decanediol in the presence of DB-
Table V. Results of homogeneous condition of sebacic acid and decanediol using 2-naphthalenesulfonic acid in the presence of DBSANa in polycondensation

\begin{tabular}{lccccc}
\hline \multicolumn{1}{c}{$\begin{array}{l}\text { Monomer } \\
\text { Condition }\end{array}$} & Time & \multicolumn{2}{c}{ Yield } & \multicolumn{2}{c}{ Molecular weight } \\
\cline { 2 - 3 } \cline { 5 - 6 } & $\mathrm{h}$ & & $M_{\mathrm{w}}$ & $M_{\mathrm{w}} / M_{\mathrm{n}}$ \\
\hline Equimolecular & 23 & 86 & & 2600 & 1.45 \\
5 mol\% excess of sebacic acid & 20 & 84 & 2400 & 1.43 \\
5 mol\% excess of decanediol & 20 & 83 & 2400 & 1.43 \\
Heterogeneous & 22 & 82 & 1900 & 1.37 \\
Used of DBSA $^{\mathrm{a}}$ & 22 & 80 & 2400 & 1.40 \\
\hline
\end{tabular}

Polycondensation; monomer concentration: $0.04 \mathrm{~mol}$ in $50 \mathrm{~g}$ of water at $80^{\circ} \mathrm{C}$. Used $2 \mathrm{~g}$ of DBSANa ( $40 \%$ in water) and $0.20 \mathrm{~g}$ of NSA. Heterogeneous; all reagents were added to water at the same time. Homogeneous: Sebacic acid, decanediol, and NSA were melted for $5 \mathrm{~min}$ at $150^{\circ} \mathrm{C}$, and then poured into water containing DBSANa at $70^{\circ} \mathrm{C}$. ${ }^{\text {a Used }} 0.20 \mathrm{~g}$ of DBSA instead of NSA.

SANa using 2-naphthalenesulfonic acid (NSA) as the catalyst of the esterification. In this case, the molecular weight of the polymers was approximately 2000 under various conditions.

The results of the high-molecular concentrations of DBSA ( $0.08 \mathrm{~mol}$ of monomers in $c a .40 \mathrm{~g}$ of water) in the polycondensation are shown Table VI. The molecular weight of polyesters increased with an increase in the amount of DBSA. Increasing DBSA (16 wt\%) in this emulsion polycondensation yield polyester having high-molecular-weight polyesters $\left(c a . M_{\mathrm{w}}=5100\right)$. These results show unreacted monomer disperse in water, but they can control the mole balance of diol and dicarboxylic acid in the misell in this polycondensation reaction. The average size of particles of the misells in the emulsion polycondensation were calculated by the laser particle analyzer, as shown Table VI, which 
Table VI. Effect for amount of DBSA on the high monomer concentration in polycondensation

\begin{tabular}{|c|c|c|c|c|c|}
\hline Amount of DBSA & Time & Yield & Molec & ar weight & Average size \\
\hline$w t \%$ & $\mathrm{~h}$ & $\%$ & $M_{\mathrm{W}}$ & $M_{\mathrm{w}} / M_{\mathrm{n}}$ & $\overline{\text { particle }(\mu \mathrm{m})}$ \\
\hline 1 & 17 & 96 & 2500 & 1.43 & 4.5 \\
\hline 2 & 17 & 87 & 2600 & 1.46 & 4.5 \\
\hline 4 & 20 & 95 & 3300 & 1.61 & 5.1 \\
\hline 8 & 23 & 85 & 3800 & 1.65 & 4.2 \\
\hline 16 & 23 & 87 & 5100 & 1.75 & 6.0 \\
\hline
\end{tabular}

Polycondensation; monomer concentration : approximate $40 \mathrm{wt} \%$ in water at $80^{\circ} \mathrm{C}$. Used $0.08 \mathrm{~mol}$ of monomers in $c a .40 \mathrm{~g}$ of water. Average size of particle; emulsion polymerization medium.

was found to be $4-6 \mu \mathrm{m}$. The esterification in water might occur in the misells having hydrophobic media from DBSA, which may play a role as the catalyst of esterification and also misell formation because DBSANa did not yield polyesters in this polycondensation reaction. A large amount of DBSA might be obtained as a fastened shell structure (surface of misell) and a small of DBSA gives a loose shell structure in this emulsion polycondensation because every misell has approximately same particle size as shown in Table VI. Therefore, the molecular weight of polyesters increases with an increase in the amount of DBSA in this emulsion polycondensation reaction. It was found that there is a good relationship between the amount of DBSA and the molecular weight of polyesters as shown in Table VI.

Table VII shows that the combination of various surfactants with sebacic acid and decanediol in the presence of an acid catalyst took place in this emulsion polycondensation. It was found that only a low yield of polyesters was obtained from non-ion surfactants or phosphate surfactant having a weak acidity with regard to DBSA under this condition. The use of DBSANa and an acid catalyst such as NSA or conc. $\mathrm{HCl}$ gave the same results in terms of the yield and molecular weight compared with the polyesters from DBSA surfactants. In the combination of DBSANa and conc. $\mathrm{HCl}$ working an ion-exchanging catalyst of DBSANa during this esterification reaction might yield a good yield and the molecular weight of polyester and more conc. hydrochloric acid can control the acidity of the medium in water. The precipitation (aggregation) of polyesters occurred when in storage for $7 \mathrm{~d}$ at room temperature because they have bigger-size particles in this emulsion polycondensation reaction and have a sulfonyl group ( $-\mathrm{SO}_{3} \mathrm{H}$ group) on the surface (shell) of the misell as shown in Table VII and Figure 1 of the misell.

It is very important to yield a good emulsion in this polycondensation to control small-size misells below $1 \mu \mathrm{m}$ in a water medium. Additional detailed studied on the emulsion polycondensation in polyesters are being carried out so as to determine the optimum reaction
Table VII. Polycondensation of various surfactants with sebacic acid and decanediol in the presence of acid catalysis in water

\begin{tabular}{|c|c|c|c|c|c|}
\hline \multirow{2}{*}{ Surfactant } & \multirow{2}{*}{ Acid Catalyst } & \multirow{2}{*}{$\frac{\text { Time }}{\mathrm{h}}$} & \multirow{2}{*}{$\frac{\text { Yield }}{\%}$} & \multicolumn{2}{|c|}{ Molecular weight } \\
\hline & & & & $\overline{M_{\mathrm{w}}}$ & $M_{\mathrm{w}} / M_{\mathrm{n}}$ \\
\hline \multirow[t]{2}{*}{$\overline{\text { DBSA }}$} & - & 23 & 86 & 2600 & 1.45 \\
\hline & c. $\mathrm{HCl}$ & 17 & 89 & 2000 & 1.44 \\
\hline \multirow{3}{*}{ DBSANa } & c. $\mathrm{HCl}$ & 22 & 85 & 3100 & 1.51 \\
\hline & NSA & 22 & 8 & 1900 & 1.37 \\
\hline & DBSA & 65 & 82 & 2100 & 1.53 \\
\hline DSANa & c. $\mathrm{HCl}$ & 26 & 66 & 2000 & 1.30 \\
\hline \multirow[t]{2}{*}{ Non-ion } & c. $\mathrm{HCl}$ & 22 & 23 & 2700 & 1.55 \\
\hline & NSA & 22 & 31 & 2500 & 1.54 \\
\hline Phosphate & - & 22 & 15 & 1000 & 1.08 \\
\hline
\end{tabular}

Polycondensation; monomer concentration: $0.02 \mathrm{~mol}$ in $50 \mathrm{~g}$ of water at $80^{\circ} \mathrm{C}$. $\mathrm{cHCl} ; 40 \%$ concentrated hydrochloric acid (used 1.0 g). DSANa; Dodecyl sulfate sodium salt. NSA; Naphtharenesulfonic acid (used 2.0 g). Non-ion; Kao Corporation Emulgen404 (polyoxyethylene alkylether). Phosphate; Di(polyethylene glycohl 4-nonylphenyl)phosphate.

condition and the mechanism in the misell involved in this process.

\section{CONCLUSION}

The synthesis of polyesters with surfactants such as $p$-dodeccylbenzenesulfonic acid (DBSA) was carried out in a water medium under mild conditions. Polyesters having medium molecular weight using aliphatic acids and diols were produced in water under a mild temperatures by this emulsion polycondensation reaction. Such polycondensation with the surfactants in water is environmentally friendly and economical since it is a non-solvent system.

\section{REFERENCES}

1. N. Ogata and H. Tanaka, Polym. J., 2, 672 (1971).

2. N. Ogata and H. Tanaka, Polym. J., 3, 365 (1972).

3. N. Ogata and H. Tanaka, Polym. J., 6, 461 (1974).

4. N. Ogata, K. Sanui, and M. Hosoda J. Polym. Sci., Polym. Chem. Ed., 17, 2401 (1970).

5. N. Yamazaki, F. Higashi, and J. Kawabata, J. Polym. Sci., 
Polym. Chem. Ed., 12, 2149 (1974).

6. G. Wu, H. Tanaka K. Sanui, and N. Ogata, J. Polym. Sci, Polym. Chem. Ed., 19, 343 (1981).

7. N. Ogata, K. Sanui, H. Tanaka, and S. Yasuda, Polym. J., 13, 989 (1981).

8. G. Wu, H. Tanaka, K. Sanui, and N. Ogata, Polym. J., 14, 797 (1982).

9. H. Tanaka, G. Wu, Y. Iwanaga, K. Sanui, and N. Ogata, Polym. J., 14, 331 (1982).

10. H. Tanaka, G. Wu, Y. Iwanaga, K. Sanui, and N. Ogata, Polym. J., 14, 635 (1982)
11. S. Kobayashi, H. Uyama, S. Suda, and N. Namekawa, Chem. Lett., 105 (1997).

12. S. Suda, H. Uyama, and S. Kobayashi, Proc. Japan. Acad., Ser. B, 75, 201 (1999).

13. K. Manabe, X. Sun, and S. Kobayashi, J. Am. Chem. Soc., 123, 10101 (2001).

14. S. Kobayashi and K. Manabe, Chemistry and Chemical Industry, 55, 471 (2002).

15. K. Manabe, S. Iimura, X. Sun, and S. Kobayashi, J. Am. Chem. Soc., 124, 11971 (2002). 